\title{
Variations in Cholinesterase activity in Oil Palm Plantation Workers Exposed to Pesticides
}

\section{ANGBO YAPO KMA ${ }^{1 *}$, CAMARA Cissé M. ${ }^{1}$, NIGUÉ L. ${ }^{2}$, SESS D. ${ }^{1}$}

\author{
${ }^{1}$ Laboratory of biochemistry, FHB University, medical sciences UFR P.O. Box V166 \\ ABIDJAN,
}

${ }^{2}$ Service of Biostatistics and medical informatics FHB University, medical sciences UFR.

\section{ARTICLE INFO}

Article No.: 011517006

Type: Research

DOI: 10.15580/GJBS.2017.1.011517006

\section{Submitted: $14 / 01 / 2017$}

Accepted: 18/01/2017

Published: $30 / 01 / 2017$

\section{${ }^{*}$ Corresponding Author}

Angbo Yapo KMA

E-mail: angeline1962@yahoo.fr

\section{Keywords:}

Biomarker. Cholinesterase activity.

Ivory Coast. Organophosphates

\section{ABSTRACT}

Pesticides including organophosphates (OPs) and carbamates are used extensively in public health and agriculture to increase crop yields. The abuse of pesticides can have a serious impact on farmer's health. The objective of this study is to study changes in serum cholinesterase activity (BChE) as a biological marker of PO poisoning. Workers in a palm tree oil unit during periods of exposure and non-exposure to pesticides, as well as a control group were selected randomly. The clinical signs reported are those observed in the subjects exposed to organophosphates and anticholinesterase carbamates. The serum enzymatic activity (AES) of cholinesterase was quantified by spectrophotometry. The average serum cholinesterase level during the exposure and non-exposure period was $4225.64 \mathrm{U} / \mathrm{I} \pm 791.10$ and $4766.47 \pm 873.32$ versus $6588.95 \mathrm{U} / \mathrm{I} \pm 1303$, respectively, 42 the control level $(n=43)(p<0.001)$. The average enzymatic activity of workers $(n=19)$ during non-exposure and exposure periods increased from $(78.95 \%)$ to non-exposure $(36.84 \%)$ (Data Not shown) with a significant difference $(p=0.00750)$. Inhibition of enzymatic activity greater than $40 \%$ was observed during the non-exposure phase in $21.05 \%$ of cases, and during the exposure period in $26.32 \%$ of cases, a bi-annual biological factor necessary for these workers. 


\section{INTRODUCTION}

The use of pesticides is currently the main control strategy to guarantee the world's food supply. Most pesticides, however, are toxic to non-target species, including humans. In order to increase the harvest and obtain better yields, pesticides are used, and among these, the most used are organophosphates (OP) and carbamates. The widespread use of organophosphates pesticides throughout the world exposes to poisoning by these chemical agents, particularly in developing countries. The mechanism of toxicity is the inhibition of acetylcholinesterase leading to an accumulation of acetylcholine and the continuous stimulation of cholinergic receptors (Kwong, 2002). The activities of plasma cholinesterases or plasma (buthrylcholinesterase) and intra-erythrocyte are the indicators used to monitor workers exposed to organophosphates, indicating the effects of cumulative exposures of previous weeks or of acute overexposure (I.N.R.S, 2012). Intensive use of these products can lead to occupational diseases and poisoning (Karlsson, 2004; Sam and al 2008; Faria and al 2009). Exposure to pesticides in agriculture is mainly through dermal and inhalation contact (IPCS, 2004), and use of personal protective equipment (PPE) may help reduce exposure levels (IPCS, 2004; Blanco and al 2005). Studies to determine knowledge, attitudes and practices (PAC) on the use of pesticides have been conducted around the world to understand the working environments and conditions in which pesticides are handled and applied by agricultural workers (Ngowi and al 2002; Recena and al 2008; Ospina and al 2009, Karunamoorthi 2011, Ribeiro 2012). The harmful effects of pesticides are divided into two categories: acute toxicity and chronic effects. The acute toxicity of pesticides generally concerns the professionals in the phytosanitary field (manufacturers and users). The work of Wesseling and al. (2010) in Costa Rica showed a relationship between acute occupational poisoning with organophosphates, and suicidal ideation. Amar and al and dasgupta and al $(2013,2007)$ found a decrease in serum cholinesterase activity as a function of years of exposure to organophosphates pesticides. A survey conducted by Kamenan in 2000 in Abidjan among industrial pesticide handlers, showed that the proportion of workers affected by organophosphate poisoning was $80.7 \%(2000)$. Data collected on the health effects of pesticides on producers indicate that the health problems associated with the use of pesticides were recurrent. Of the 42 health centers surveyed, 922 cases of pesticide poisoning since 2002 have been identified. Each year, the national health laboratory records 800 cases of poisoning ( 5 to $10 \%$ ) of cases due to pesticides.

The objective of this work is to determine changes in cholinesterase activity in order to assess the levels of poisoning of workers to organophosphates pesticides and carbamates according to the period of exposure.

\section{MATERIALS AND METHODS}

This prospective study was conducted in Abidjan (Côte d'Ivoire) in a palm oil farming unit from January to October 2016.

\section{Inclusion Criteria}

The study included on one hand, cases of workers who had been in contact with phytosanitary products during the storage, preparation, spreading, disposal of residues and supervision of, and who observed a period of non-exposure varying between 1 and 3 months and, on the other hand, of persons having no regular contact with these products, and who came from the staff of the UFR values of normal biochemical parameters (blood glucose, urea, creatinine, transaminases, hemoglobin). Indeed, the biochemical parameters were assayed to eliminate anything that could contribute to a misinterpretation of the results of cholinesterase, since the cholinesterase activity is usually associated with liver damage, Anemia, a congenital deficiency, and an organophosphates poisoning in this case, there is first a decrease in serum activity and then a decrease in the globular activity. An increase in activity is observed in the case of nephrotic syndrome (Biommis 2012).

\section{Informed consent for both cases and witnesses}

For each person who meets our inclusion criteria, a fact sheet containing socio-demographic characteristics, professional information, pesticide application conditions, and clinical aspects has been completed. After information, informed consent, a promise of confidentiality and a return of information, a blood sample for the biological examinations was made. In this study, a worker is considered to be in the exposure period up to 5 days after pesticide use, and, within the non-exposure period after 1 month of non-use of pesticides.

\section{Samples}

The blood collected by venipuncture in fasting morning subjects was collected in dry Vacutainer tubes for the determination of urea, creatinine, transaminases and cholinesterase, tubes containing potassium oxalate and Fluoride for the determination of blood glucose and in tubes containing EDTA for hemoglobin $(\mathrm{Hb})$. In cases: there were 2 withdrawals: 1st in exposure period and 2nd withdrawal in nonexposure period 1 to 3 months after a period of nonexposure. Samples were immediately conveyed to the laboratory in coolers containing carbo-ice. Tubes without anticoagulants and those containing 
potassium oxalate and fluoride were centrifuged (centrifuge 5804) at $3000 \mathrm{rpm}$ for $3 \mathrm{~min}$ for analysis.

\section{Dosage}

The parameters concerned are: blood glucose, urea, creatinine, transaminases, and hemoglobin which have been assayed as inclusion assay and cholinesterase. The hemoglobin assay was performed by the Sysmex KX-21N® hematology machine while all other parameters were analyzed by colorimetric methods with a HITACHI 902 autoanalyzer. The AES of serum cholinesterase was evaluated by spectrophotometry with kinetic reading. The dosage principle is as follows: Cholinesterase catalyzes the hydrolysis of butyrylthiocholine to butyrate and thiocholine. Thiocholine reacts with 5,5'dithiobis-2-nitrobenzoic acid (D.T.N.B) to form nitro-2mercapto-5-benzoate. The concentration of the product formed which is measured at $405 \mathrm{~nm}$ is proportional to the enzymatic activity of the cholinesterase present in the sample to be assayed. The normality range is between 4,640 $-11,120 \mathrm{U} / \mathrm{L}$ for a reaction temperature of $37^{\circ} \mathrm{C}$.

\section{Statistical Analysis}

Statistical analysis of the data was carried out using the Epi info 7 software. The relationship between serum cholinesterase and professional seniority was investigated using the Pearson correlation test. The relationship between clinical symptoms reported by workers and serum cholinesterase was investigated by the Student or Kruskal Wallis test, depending on the case. The study of the relationship between serum cholinesterase and the use of P.P.E was carried out by the Student or Kruskal Wallis test. The significance level was set at $95 \%(p<0.05)$. The average was compared with the Student test.

\section{RESULTS}

Socio-demographic and professional characteristics

\section{Gender}

The study population consisted of 19 males.

\section{Age}

The average age was 41 years \pm 7.49 for people exposed and non-exposed, and $37.95 \pm 11.99$ for controls. The difference in age was not significant ( $p$ $=0.14)$.

\section{Professional seniority}

Average professional tenure was $15 \pm 10.03$ years with extremes of 2 to 37 years and had no correlation with the mean serum cholinesterase level at both the exposure and non-exposure periods.

\section{Personal Protective Equipment (P.P.E)}

For P.P.E use, $91.6 \%$ of workers were negatively correlated with the mean cholinesterase level during the exposure and non-exposure period.

\section{Biological results}

Mean values of cholinesterase in the study population

The mean values of cholinesterase in the study population are as follows:

Table 1: Mean serum cholinesterase levels in exposed and controlled subjects

\begin{tabular}{|lccc|}
\hline & exposure period & non-exposure period & Control subjects \\
\hline Workforce & 19 & 19 & 43 \\
Minimum value $(\mathrm{U} \Lambda)$ & 2799 & 3114 & 4640 \\
Maximum value $(\mathrm{U} \Lambda)$ & 6404 & 6300 & 11120 \\
Average value $(\mathrm{U} \Lambda)$ & 4225.65 & 4766 & 6588.95 \\
Median & 4213 & 4999 & 6275 \\
\hline
\end{tabular}

The mean serum cholinesterase (BChE) level in exposed individuals was $4248.47 \mathrm{U} / \mathrm{I} \pm 829.53$ during the exposure phase and $4766 \pm 873.32$ during the non-exposure phase and that of the controls was $6588.95 \cup / I \pm 1303.42$ (Table 1). The average worker's BChE activity $(n=19)$ during exposure and non-exposure periods was significantly lower than for controls $(n=43)$. The comparison of these means with that of the controls showed a significant difference $(p<0.001)$. Comparison of worker averages during exposure and non-exposure periods gave a significant difference $p=0.01689$.

\section{Variation of inhibition of enzymatic activity during the non-exposure phase}

Variations in the inhibition of enzymatic activity during the non-exposure phase were shown in the table below: 
Table 2: Variation of the inhibition of the enzymatic activity during the non-exposure phase

\begin{tabular}{|lll|}
\hline Inhibition Degree & Frequency & Percentage \\
\hline Strong & 4 & $21.05 \%$ \\
Moderate & 3 & $15.79 \%$ \\
Normal & 12 & $63.16 \%$ \\
Total & 19 & $100 \%$ \\
\hline
\end{tabular}

The inhibition of enzymatic activity during the non-exposure phase was normal in the majority of cases (63.16\%).

\section{Variation of the inhibition of the enzymatic activity during the exposure phase}

Variations in the inhibition of enzymatic activity during the exposure phase were shown in the table below:

Table 3: Variation of the inhibition of the enzymatic activity during the exposure phase

\begin{tabular}{|lll|}
\hline Inhibition degree & Frequency & Percentage \\
\hline Strong & 5 & $26.32 \%$ \\
Moderate & 10 & $52.63 \%$ \\
Normal & 4 & $21.05 \%$ \\
Total & 19 & $100.00 \%$ \\
\hline
\end{tabular}

The inhibition of enzymatic activity during the exposure phase was moderate in the majority of cases $(52.63 \%)$.

Note:

Normal inhibition: $<30 \%$

Moderate Inhibition: $30-40 \%$

High inhibition: $>40 \%$

\section{Comparison average value of cholinesterase and reported symptoms}

Comparison of average cholinesterase value before exposure and post-exposure with symptoms reported by workers gave a non-significant difference $(p=0.5)$

\section{Comparison average value of cholinesterase and occupational seniority}

Comparison of the average value of cholinesterase before exposure and post-exposure with occupational seniority gave a non-significant difference $(p=0.95)$

\section{Comparison of Mean Value of Cholinesterase and Use of P.P.E}

Comparison of the mean value of cholinesterase before exposure with exposure to occupational seniority gave a non-significant difference $(p=0.43)$

\section{DISCUSSION}

\section{Socio-demographic and occupational} characteristics

\section{Gender}

All workers (100\%) were male. The absence of women is due to the fact that the selected population was the one handling the plant protection products and in this undertaking this population is made up entirely of men. Our findings are consistent with those of Manda and al. (2010) who found $100 \%$ male subjects in their work.

\section{Age}

We found that the subjects in our series were adults with an average age of 41 years. These results are in agreement with those of Juliana and al. (2012) who found an average age of 41 years for people exposed and non-exposed. The difference in age was not significant $(p=0.14)$.

\section{Use of EPI}

With regard to the use of P.P.E, 91.6\% of workers were employed. This result is different from some previous studies. Indeed, studies conducted by (Snelder and al 2008 Doumbia and Kwadjo, 2009) revealed that market gardeners protect themselves very little during treatment.

\section{Organic Results}

Mean values of cholinesterase in the study population 
The average worker's BChE activity $(n=19)$ during exposure and non-exposure periods was significantly lower than for controls $n=43(P<0.001)$ (Table 1)..The comparison of the averages of the workers during the exposure and non-exposure periods gave a significant difference $p=0.01689$. Our results are different from those of (Juliana et al. 2012; Bulgaroni and al. 2012; Joshaghani and al. 2007) who found no significant difference between the average activities of the farmer group during non-exposure periods and exposure periods.

\section{Variation of the inhibition of the enzymatic activity during both phases}

Enzyme inhibition of butyrylcholinesterase was considered normal when the rate was < 30\%, moderate between $30 \%$ and $40 \%$, and severe when > $40 \%$. Severe inhibition corresponds to a very great decrease in enzymatic activity, moderate inhibition corresponds to an average decrease in enzymatic activity, and normal inhibition to an enzymatic activity, the decrease of which is insignificant. Normal inhibition was $(63.16 \%)$ and $(21.05 \%)$, respectively, during the non-exposure phase and during the exposure phase. Severe inhibition during the nonexposure and exposure phase was $(21.05 \%)$ and $(26.32 \%)$, respectively. Moderate inhibition was $(15.79 \%)$ and $(52.63 \%)$, respectively (Table $2-3)$. We observe that inhibition of enzymatic activity is higher in the majority of the population during the exposure phase $(78.95 \%)$ than in the non-exposure phase $(36.84 \%)$ with a significant difference $(P=0.0075)$. Our findings are consistent with Juliana et al. (2012) who found the majority of workers that had $\pm 30 \%$ variation in enzymatic activity during the exposure period. For Fournier et al., (1970), decreases in blood activity of 50 to $70 \%$ of exposed individuals can be observed without associated clinical signs. Our results showed a reduction in serum cholinesterase activity of more than $40 \%$ during the exposure and non-exposure phase, respectively, in 5 and 4 workers, with an inhibition of $30 \%$ in 3 and 10 workers respectively (Table $2-3$ ).

According to the International Labor Organization (I.L.O.), a reduction of serum cholinesterase greater than $40 \%$ results in the withdrawal of the subject and his transfer to another post until the cholinesterase level (OIT, 2010).

\section{Mean Cholinesterase Value Comparison}

Comparison of the mean value of cholinesterase with clinical symptoms, professional age and use of PPE showed a non-significant difference. Our results agree with Juliana et al., (2012) who also found no significant correlation.

\section{CONCLUSION}

Organophosphates pesticides, which are widely used in agriculture, can be a source of intoxication among workers. Consequently, good action (compliance with hygiene measures and instructions on the safety of use of pesticides) during their use is necessary to minimize the risk of poisoning. In our study, during the exposure phase and the non-exposure phase, no positive correlation was found between the average cholinesterase level and the professional age, the clinical signs observed, and the use of PPE. A significant difference was found between the mean cholinesterase level during the exposure, nonexposure and controls. The inhibition of BChE activity during the exposure period and the non-exposure period was higher for some workers indicating that they could be exposed to pesticides during their agricultural activities. In addition, some had higher activity during periods of exposure than nonexposure. It is necessary to sensitize those responsible for this agricultural unit in order to carry out a semi-annual biological evaluation of these workers as recommended by the WHO (1979) for subjects exposed to organophosphates and carbamates. Further studies should be conducted on a larger number of workers in order to have a more representative conclusion.

\section{CONFLICTS OF INTEREST}

The authors state that they have no conflicts of interest.

\section{AUTHORS CONTRIBUTIONS}

AYKMA initiated this study and took part in the collection of field data, analysis of the data, discussion and drafting of the manuscript. CC initiated this study and supported the discussion of the results and made corrections to the manuscript. NL participated in data processing. SD initiated this study.

\section{THANKS}

Our thanks to head Managers of the palm oil unit for facilitating access to the study site and the applicators for agreeing to participate in the study.

\section{REFERENCES}

Amar, S. D.; and Suman, S. (2013): Assessment of Serum Cholinesterase in Rural Punjabi Sprayers Exposed to a Mixture of Pesticides. Toxicol Int. 20, (2)154-159. doi: 10.4103/0971-6580.117258.

Biommis. (2012) : Précis de Biopathologie Analyses Médicales spécialisées http://www.biomnis.com/referentiel/liendoc/precis/ EBV.pdf

Blanco, L. E.; Aragón A.; Lundberg, I.; Lidén, C.; Wesseling, C.; Nise, G. (2005): Determinants of dermal exposure among Nicaraguan subsistence 
farmers during pesticide applications with backpack sprayers. Ann. Occup. Hyg, 49, 17-24. https://annhyg.oxfordjournals.org/content/49/1/17. full

Bulgaroni, V.; Rovedatti, M. G.; Sabino, G.; Magnarelli, G. (2012): Organophosphate pesticide environmental exposure: analysis of salivary cholinesterase and carboxilesterase activities in preschool children and their mothers. Environ Monit Assess. 184, (5) 3307-14. doi: 10.1007/s10661-011-2190-8.

Dasgupta, S.; Meisner, C.; Wheeler, D.; Xuyen, K.; Thi, L.N. (2007): Pesticide poisoning of farm workers-implications of blood test results from Vietnam. Int J Hyg Environ Health. 210, (2) 12132. doi:10.1016/j.jijheh.2006.08.006.

Doumbia, M., and Kwadjo, K. E. (2009): Pratiques d'utilisation et de gestion des pesticides par les maraîchers en Côte d'Ivoire : Cas de la ville d'Abidjan et deux de ses banlieues (Dabou et Anyama). Journal of Applied Biosciences. 18, 992 $-1002$.

Faria, N. M. X.; Rosa, J. A. R.; Facchini, L. A. (2009): Poisoning by pesticides among family fruit farmers, Bento Gonçalves, Southern Brazil. Rev. Saude Publ. 43, 335-344. doi: 10.1590/S003489102009005000014.

Fournier, E. and Gervais, P. (1970): Dictionnaire des intoxications. Pars : Ed Heures de France, 669.

Institut national de recherche et de sécurité, (I.N.R.S). (2012): Organophosphorés, Nature du dosage: Cholinestérases intraérythrocytaires. http://www.inrs.fr/dms/inrs/CataloguePapier/ED/TI -ED-4451/ed4451.pd

International Programme on Chemical Safety, (IPCS). (2004): Guidelines on the Prevention of Toxic Exposures. Education and Public Awareness Activities. World Health Organization; Geneva, Switzerland. [(accessed on 24 March 2016)].Available online: http://www.Who.Int/Ipcs/Features/Prevention_Gui delines.Pdf

Joshaghani, H. R.; Ahmadi. A. R.; Mansourian, A.R. (2007): Effects of occupational exposure in pesticide plant on workers' serum and erythrocyte cholinesterase activity. Int J Occup Med Environ Health. 20, (4) 381-5. doi: 10.2478/v10001-0070039-8.

Juliana, O. P.; Priscila, T.; Juciê, R. S.; Bruno Z. D.; Eloisa, D. C. (2012): Knowledge, Attitudes, Practices and Biomonitoring of Farmers and Residents Exposed to Pesticides in Brazil Int $J$ Environ Res Public Health. 9, (9) 3051-3068. doi: 10.3390/ijerph9093051

Kamenan, E. J. (2000): Evaluation de l'exposition des insecticides organophosphorés chez les manipulateurs de pesticides en milieu industriel à Abidjan: Thèse pharmacie Abidjan, $369 \mathrm{p}$.

Karlsson, S. I. (2004): Agricultural pesticides in developing countries A multilevel governance challenge. Environment. 46, 22-41. doi: $10.1080 / 00139150409604382$
Karunamoorthi, K.; Mohammed, A.; Jemal, Z. (2011): Peasant association member's knowledge, attitudes, and practices towards safe use of pesticide management. Am. J. Ind. Med. 54, 965970. doi: 10.1002 /ajim.21008

Kwong, T. C. 1. (2002): Organophosphate pesticides: biochemistry and clinical toxicology. Ther Drug Monit. Feb; 24, (1) 144-9. https://www.ncbi.nlm.nih.gov/pubmed/11805735

Manda, P.; Dano, D.; Sébastien, K. M.; Mansour, A. F. (2010): Control of the Cholinesterases of the Pesticides Applicators in Abidjan (Côte d'Ivoire). European Journal of Scientific Research, 39 (2):176-82.ISSN1450-

216XEuroJournalsPublishing,

Inc http://www.eurojournals.com/ejsr.htm

Ngowi, A.V.; Maeda, D. N.; Partanen, T.J. (2002): Knowledge, attitudes and practices (KAP) among agricultural extension workers concerning the reduction of the adverse impact of pesticides in agricultural areas in Tanzania. Med. Lav. 93, 338-346.

https://www.ncbi.nlm.nih.gov/pubmed/12212403

Organisation Internationale de Travail, (O. I. T) (2010): Programme des activités sectorielles ; Recueil de directives et pratiques sur la sécurité et la santé dans l'agriculture, Genève.

Organisation Mondiale de la Santé. (1979). Sécurité d'emplois des pesticides, Word Health Organ Tech Rep Ser (634) 49. http://apps.who.int/iris/bitstream/10665/40742/1/9 242561398

Ospina, J. M.; Manrique Abril, F.G.; Ariza, N. E. (2009): Educational intervention concerning knowledge and practices regarding work-related risks in potato farmers in Boyacá, Colombia. Rev. Salud Publ.11, 182-190. doi: 10.1590/S012400642009000200003.

Recena, M. C. P.; Caldas, E. D. (2008): Risk perception, attitudes and practices on pesticide use among farmers of a city in Midwestern Brazil. Rev. Saude Publ. 42, 294-301. http://www.scielo.br/scielo

Ribeiro, M. G.; Colasso, C. G.; Monteiro, P. P.; Filho, W.R.; Yonamine, M. (2012) Occupational safety and health practices among flower greenhouses workers from Alto Tietê region (Brazil) Sci. Total Environ. 416, 121-126. doi: 10.1016/j.scitotenv.2011.11.002.

Sam, K. G.; Andrade, H. H.; Pradhan, L.; Pradhan, A.; Sones, S. J.; Rao, P. G. M.; Sudhakar, C. (2008): Effectiveness of an education program to promote pesticides safety among pesticides handlers of South Índia. Int. Arch. Occup. Environ. Health. 81, 787-795. doi: 10.1007/s00420-007-0263-3.

Snelder, D. J.; Masipiqueña, M. D.; and de Snoo, G. R. (2008): Risk assessment of pesticide usage by smallholder farmers in the Cagayan Valley (Philippines).Crop Prot 27, 747-762.

Wesseling, C.; van Wendel de J. B.; Keifer, M.; London, L.; Mergler, D.; Stallones, L. (2010): 
Symptoms of psychological distress and suicidal ideation among banana workers with a history of poisoning by organophosphate or n-methyl carbamate pesticides. Occup Environ Med 67,

(11) 778-84. doi: 10.1136 / oem.2009.047266.

Cite this Article: Angbo Yapo KMA, Camara Cissé M, Nigué L, Sess D (2017). Variations in Cholinesterase activity in Oil Palm Plantation Workers Exposed to Pesticides. Greener Journal of Biological Sciences, 7(1):008-014, http://doi.org/10.15580/GJBS.2017.1.011517006. 